\title{
Imaging modalities to assess oxygen status in glioblastoma
}

\author{
Aurélien Corroyer-Dulmont ${ }^{1,2,3,4 *}$, Ararat Chakhoyan ${ }^{1,2,3,4}$, Solène Collet ${ }^{1,2,3,4}$, \\ Lucile Durand ${ }^{1,2,3,4}$, Eric T. MacKenzie ${ }^{1,2,3,4}$, Edwige Petit ${ }^{1,2,3,4}$, Myriam Bernaudin ${ }^{1,2,3,4}$, \\ Omar Touzani $i^{1,2,3,4}$ and Samuel Valable $1,2,3,4 *$
}

${ }^{1}$ CNRS, UMR 6301-Imagerie et stratégies thérapeutiques des pathologies cérébrales et tumorales (ISTCT), CERVOxy group, GIP Cyceron, Caen, France, ${ }^{2}$ CEA, Direction des Sciences du Vivant (DSV)/Institut d'Imagerie Biomédicale (I2BM), UMR 6301-Imagerie et stratégies thérapeutiques des pathologies cérébrales et tumorales (ISTCT), CERVOxy group, GIP Cyceron, Caen, France, ${ }^{3}$ Université de Caen Normandie, UMR 6301-Imagerie et stratégies thérapeutiques des pathologies cérébrales et tumorales (ISTCT), CERVOxy group, GIP Cyceron, Caen, France, ${ }^{4}$ Esplanade de la Paix, Normandie Université, Caen, France

\section{OPEN ACCESS}

Edited by:

Michel Chérel,

University of Nantes, France

Reviewed by:

Serge Goldman,

Université Libre de Bruxelles Hôpital

Érasme, Belgium

Amandine Pallardy,

Centre Hospitalier Universitaire de

Nantes, France

*Correspondence:

Aurélien Corroyer-Dulmont and

Samuel Valable,

UMR 6301-ISTCT, GIP Cyceron,

Bd H Becquerel, BP 5229,

Caen Cedex 14074, France

aurelien.dulmont@gmail.com; valable@cyceron.fr

Specialty section:

This article was submitted to Nuclear Medicine, a section of the journal

Frontiers in Medicine

Received: 11 June 2015

Accepted: 03 August 2015

Published: 19 August 2015

Citation:

Corroyer-Dulmont A, Chakhoyan A,

Collet S, Durand L, MacKenzie ET,

Petit E, Bernaudin M, Touzani $O$ and Valable S (2015) Imaging modalities to assess oxygen status in glioblastoma.

Front. Med. 2:57.

doi: 10.3389/fmed.2015.00057
Hypoxia, the result of an inadequacy between a disorganized and functionally impaired vasculature and the metabolic demand of tumor cells, is a feature of glioblastoma. Hypoxia promotes the aggressiveness of these tumors and, equally, negatively correlates with a decrease in outcome. Tools to characterize oxygen status are essential for the therapeutic management of patients with glioblastoma (i) to refine prognosis, (ii) to adapt the treatment regimen, and (iii) to assess the therapeutic efficacy. While methods that are focal and invasive in nature are of limited use, non-invasive imaging technologies have been developed. Each of these technologies is characterized by its singular advantages and limitations in terms of oxygenation status in glioblastoma. The aim of this short review is, first, to focus on the interest to characterize hypoxia for a better therapeutic management of patients and, second, to discuss recent and pertinent approaches for the assessment of oxygenation/hypoxia and their direct implication for patient care.

Keywords: hypoxia, glioblastoma, MRI, PET, multimodal imaging

\section{Hypoxia and Glioblastoma}

As an aggressive solid tumor, glioblastoma (GBM) presents cardinal histological features of chaotic microvascular proliferation and necrotic foci. However, the neoangiogenesis is dysfunctional and normal tissue oxygen tension is not maintained (1). The resulting imbalance between oxygen consumption and supply is called hypoxia. An important spatial heterogeneity is observed in GBM with severely hypoxic zones and peripheral infiltration accompanied by a microvascular proliferation (2). GBM cells, in hypoxic conditions, express transcriptional factors, such as the hypoxia-inducible factor (HIF), which, by the induction of various gene expressions, is involved in tumor cell adaptation. Hypoxia plays a pivotal role in the spread of tumor cells and, hence, invasion (3). Hypoxia is also a key factor in the rapaciousness of human GBM and the characterization of hypoxia discriminates poor from long outcomes (4). Moreover, hypoxia greatly impacts therapeutic efficacy. For instance, it is known that the degree of oxygenation is critical for the efficacy of both radiation therapy and chemotherapy (5). All these aspects are summarized in Figure 1.

Abbreviations: BLI, bioluminescence imaging; EPR, electron paramagnetic resonance; GBM, glioblastoma; HB, hemoglobin; HIF, hypoxia-inducible factor; MRI, magnetic resonance imaging; NIRS, near infrared spectroscopy; PET, positron emission tomography; $\mathrm{p}_{\mathrm{t}} \mathrm{O}_{2}$, tissular oxygen pressure; $\mathrm{SO}_{2}$, oxygen saturation. 


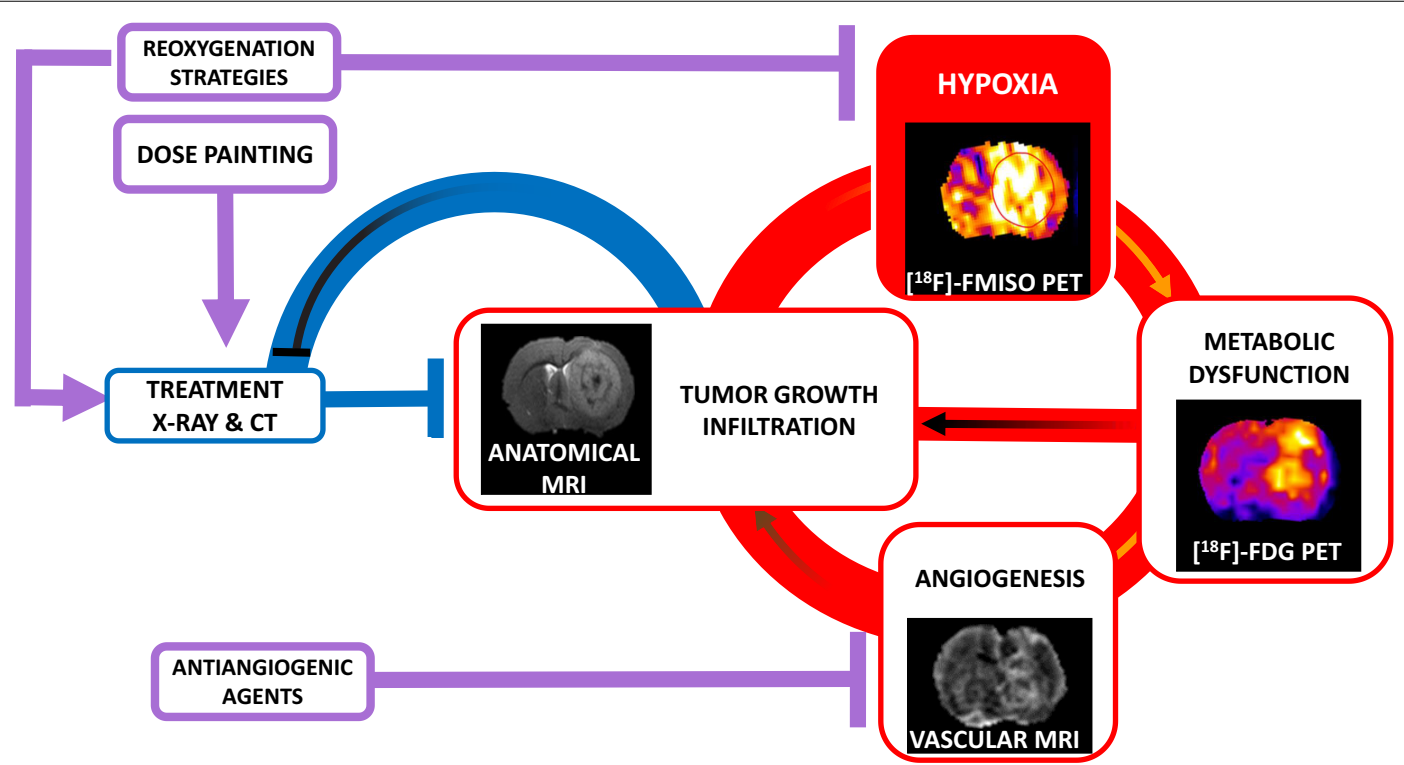

FIGURE 1 | Schematic representation of the negative role of hypoxia in tumor growth and therapeutic response in glioblastoma. The growth of a GBM is a feed-forward (vicious) cycle exacerbated by hypoxia as depicted in red. Hypoxia renders the tumor less susceptible to standard chemo-(CT) and radio-therapy (X-ray) as shown in blue. Future treatment strategies are indicated in purple.
Hence, the assessment of tissue oxygen tension in GBM is crucial to personalize the treatment for each patient and to monitor its efficacy. Various methods, more or less invasive (Table 1), have been developed to assess the level of oxygenation at different compartments ranging from blood to cells.

\section{Identification of Hypoxia at the Molecular Scale: Immunohistochemistry}

Evaluation of hypoxia at the molecular scale can be performed by the detection of hypoxia-activated endogenous molecules, such as HIF $\alpha$, and its targets, such as CAIX, Glut1, and VEGF. Another approach is to detect pimonidazole uptake in cells after systemic administration prior to biopsy. Immunohistochemistry has demonstrated its usefulness in the classification of GBM patients as a function of the level of hypoxia within the tumor and then predict recurrence and overall survival (4). The limitation to this technique is its invasive nature and the approach is restricted to a small biopsy, which may be not representative of the entire tumoral mass. Ideally and given the temporo-spatial heterogeneity of GBM, a method able to continuously and repeatedly assess hypoxia by three-dimensional imaging would be more than desirable.

\section{Assessment of Local Tissue Oxygenation: Intracerebral Probes}

The most direct assessment of tissue oxygenation is to measure the regional tissular oxygen pressure $\left(\mathrm{p}_{\mathrm{t}} \mathrm{O}_{2}\right)$ by probes implanted directly into the brain. The first probe developed was the Eppendorf polarographic $\mathrm{p}_{\mathrm{t}} \mathrm{O}_{2}$ electrode, which relies on the measurement of the current generated at a cathode coated with thin gold by ionization of oxygen at $-700 \mathrm{mV}$. The needle is mounted on a stepping motor that sequentially advances and retracts the needle tip. This approach allows the creation of a histogram of $\mathrm{p}_{\mathrm{t}} \mathrm{O}_{2}$ recorded from the tissue of interest. The temporal assessment of $\mathrm{p}_{\mathrm{t}} \mathrm{O}_{2}$ is possible but the electrochemical reduction reduces the dissolved oxygen causing a continuous signal decrease with time. A second probe, more recently used, is the OxyLite ${ }^{\mathrm{TM}}$ probe (Oxford-Optronix). Light pulses carried by an optical fiber induce pulsatile fluorescence of a ruthenium luminophore incorporated into a silicone rubber polymer at the probe tip. The lifetime of the fluorescent pulses is inversely proportional to the oxygen tension in the tip. In a syngeneic model of rhabdomyosarcoma, the sensitivity of this method was exemplified by a real-time variation of tumor $\mathrm{p}_{\mathrm{t}} \mathrm{O}_{2}$ during induced hypercapnia (6).

Despite the fact that oxygen sensitive probes allow a direct assessment of $\mathrm{p}_{\mathrm{t}} \mathrm{O}_{2}$, their major limitation is that they only allow a focal measurement of $\mathrm{O}_{2}$ tensions. It is not possible to ascertain the exact location of the probe, e.g., in a necrotic or a peripheral area of the tumor. A second disadvantage is the invasiveness of these probes, which are unlikely to have clinical applications. Finally, there is also the fact that histography consumes oxygen.

\section{Assessment of Hypoxia in Glioblastoma with Imaging}

Several imaging methods have been developed to assess oxygen status in GBM patients but two main approaches are widely employed and based on MRI and PET technologies. These methods evaluate the level of oxygen in different physiological compartments: blood vessels (oxygen saturation, $\mathrm{SO}_{2}$ ), tissue $\left(\mathrm{p}_{\mathrm{t}} \mathrm{O}_{2}\right)$, or cellular level and can thus render directly or indirectly indices of oxygenation. 
TABLE 1 | Methodological approaches to evaluate oxygenation in glioblastoma: advantages and limitations.

\begin{tabular}{|c|c|c|}
\hline & Advantages & Limitations \\
\hline Immunohistochemistry & Routinely performed in neuropathology labs & $\begin{array}{l}\text { Indirect assessment of } \mathrm{p}_{\mathrm{t}} \mathrm{O}_{2} \\
\text { Invasive and localized }\end{array}$ \\
\hline Probes & Direct and quantitative assessment of $\mathrm{p}_{\mathrm{t}} \mathrm{O}_{2}$ & $\begin{array}{l}\text { Invasive and localized } \\
\text { Low reproducibility } \\
\text { Consumption of oxygen (for Eppendorf probes) }\end{array}$ \\
\hline NIRS & $\begin{array}{l}\text { Setup and application in clinical routine are easy } \\
\text { No contrast agent injection }\end{array}$ & $\begin{array}{l}\text { Indirect assessment of } \mathrm{p}_{\mathrm{t}} \mathrm{O}_{2} \\
\text { Superficial and regional }\end{array}$ \\
\hline qBOLD & $\begin{array}{l}\text { Setup and application in clinical routine are easy } \\
\text { Whole brain characterization } \\
\text { Sensitive }\end{array}$ & $\begin{array}{l}\text { Indirect assessment of } \mathrm{p}_{\mathrm{t}} \mathrm{O}_{2} \\
\text { Specificity for hypoxia needs to be validated }\end{array}$ \\
\hline$\left[{ }^{19} \mathrm{~F}\right]-\mathrm{MRI}$ & Direct and quantitative assessment of $\mathrm{p}_{\mathrm{t}} \mathrm{O}_{2}$ & $\begin{array}{l}\text { Needs contrast agent injection potentially toxic } \\
\text { Needs }{ }^{19} \mathrm{~F} \text { coil (not easy for clinic application) } \\
\text { Relatively low spatial resolution }\end{array}$ \\
\hline EPR imaging & $\begin{array}{l}\text { Direct and quantitative assessment of } \mathrm{p}_{\mathrm{t}} \mathrm{O}_{2} \\
\text { Whole brain characterization }\end{array}$ & $\begin{array}{l}\text { Localized (for EPR) } \\
\text { Very low spatial resolution } \\
\text { No studies in brain tumors }\end{array}$ \\
\hline MOBILE & Whole brain characterization & $\begin{array}{l}\text { Indirect and relative assessment of } \mathrm{p}_{\mathrm{t}} \mathrm{O}_{2} \\
\text { No studies in brain tumors }\end{array}$ \\
\hline Bioluminescence imaging & Indicator of cellular hypoxia & $\begin{array}{l}\text { Needs genetically engineered tumor cells } \\
\text { Not applicable for patients }\end{array}$ \\
\hline${ }^{15}$ Oxygen & Whole brain characterization & $\begin{array}{l}\text { Administration of a gaseous radioactive contrast agent } \\
\text { No linear relation between oxygen consumption and cellular hypoxia }\end{array}$ \\
\hline$\left[{ }^{62} \mathrm{Cu}\right] /\left[{ }^{64} \mathrm{Cu}\right]-\mathrm{ATSM}$ & $\begin{array}{l}\text { Characterization of moderate hypoxia } \\
\text { Whole brain characterization }\end{array}$ & $\begin{array}{l}\text { Injection of a radioactive contrast agent } \\
\text { Long half-life }(12.7 \mathrm{~h}) \\
\text { Specificity for hypoxia is discussed }\end{array}$ \\
\hline$\left[{ }^{18} \mathrm{~F}\right]-\mathrm{FMISO}$ & $\begin{array}{l}\text { Indicator of cellular hypoxia } \\
\text { Particularly adapted to radiation therapy modulation } \\
\text { Whole brain characterization }\end{array}$ & $\begin{array}{l}\text { Injection of a radioactive contrast agent } \\
\text { Relative long time before steady-state acquisition ( } 2 \mathrm{~h} \text { ) }\end{array}$ \\
\hline$\left[{ }^{18} \mathrm{~F}\right]-\mathrm{FAZA}$ & $\begin{array}{l}\text { Indicator of cellular hypoxia } \\
\text { More rapid clearance than }\left[{ }^{18} \mathrm{~F}\right] \text {-FMISO } \\
\text { Whole brain characterization }\end{array}$ & $\begin{array}{l}\text { Injection of a radioactive contrast agent } \\
\text { Needs to be validated in a greater number of studies }\end{array}$ \\
\hline$\left[{ }^{18} \mathrm{~F}\right]-\mathrm{H} X 4$ and $\left[{ }^{18} \mathrm{~F}\right]$-FETNIM & $\begin{array}{l}\text { Indicator of cellular hypoxia } \\
\text { Whole brain characterization }\end{array}$ & $\begin{array}{l}\text { Injection of a radioactive contrast agent } \\
\text { Not recommended for brain tumors }\end{array}$ \\
\hline$\left[{ }^{18} \mathrm{~F}\right]-\mathrm{EF} 5$ & $\begin{array}{l}\text { Indicator of cellular hypoxia } \\
\text { Sensitivity near to immunohistochemistry } \\
\text { Whole brain characterization }\end{array}$ & $\begin{array}{l}\text { Injection of a radioactive contrast agent } \\
\text { Synthesis of radiotracer remains difficult }\end{array}$ \\
\hline$\left[{ }^{18} \mathrm{~F}\right]-\mathrm{RP}-170$ & $\begin{array}{l}\text { Reflect of cellular hypoxia } \\
\text { Whole brain characterization }\end{array}$ & $\begin{array}{l}\text { Injection of a radioactive contrast agent } \\
\text { Needs to be validated in a greater number of studies }\end{array}$ \\
\hline
\end{tabular}

\section{Estimation of Tumor Hypoxia in the Vascular Compartment: NIRS and BOLD-MRI}

\section{Near Infrared Spectroscopy}

Near infrared spectroscopy (NIRS) is a simple, non-invasive but indirect method to characterize the level of oxygenation in blood. Hemoglobin $(\mathrm{Hb})$ has an important photon absorption level in the near infrared range. The absorption spectrum is different if the hemoglobin is fully oxygenated or fully deoxygenated (deoxyHb). NIRS is able to characterize the concentration of the different forms of hemoglobin to reflect oxygen saturation (7). However, the NIRS characterization is superficial and is only reliable to a depth of 3-5 $\mathrm{mm}$ in the adult.

\section{Blood Oxygen Level-Dependent MRI}

Blood oxygen level-dependent MRI (BOLD-MRI) is a tomographic approach to detect changes in paramagnetic deoxyHb.
From the complex relationship between $\mathrm{T}^{*}$ and the $\mathrm{Hb} / \mathrm{deoxyHb}$ ratio, a method to measure the $\mathrm{SO}_{2}$ has been developed and termed as qBOLD-MRI where "q" stands for quantitative. The relationship between the $\mathrm{T}^{*}$ signal and $\mathrm{SO}_{2}$ is multifactorial and depends on several parameters, such as cerebral blood volume $(\mathrm{CBV})$, local hematocrit, $\mathrm{T} 2$ value, $B_{0}$ field, and oxygen saturation (8). With the quantification and integration of these parameters, a $\mathrm{SO}_{2}$ map can be obtained. At a preclinical level, Christen and colleagues (8) have demonstrated the sensitivity of this method to detect changes not only in brain oxygenation during hypoxemia episodes but also in murine orthotopic models of GBM (9). Given that anatomical MRI is in use routinely, additional scan time to characterize tumor hypoxia by qBOLD-MRI could yield meaningful clinical data. The ready accessibility of MRI tempts one to use BOLD-MRI to assess hypoxia. However, BOLD-MRI, entirely focused on the vascular compartment $\left(\mathrm{SO}_{2}\right)$, corresponds to an indirect assessment of oxygenation in tissue. While the use of qBOLD-MRI corrects some pitfalls in the standard BOLD-MRI technique (10), the specificity of this approach for hypoxia still 
requires validation. Indeed, $\mathrm{SO}_{2}$ and $\mathrm{p}_{\mathrm{t}} \mathrm{O}_{2}$ are non-linear and various parameters affect the sigmoid shape of the relationship between the two parameters. Nonetheless, the extrapolation of $\mathrm{p}_{\mathrm{t}} \mathrm{O}_{2}$ from $\mathrm{SO}_{2}$ is feasible under physiological circumstances, it is highly critical in a tumoral environment with several disturbed metabolic processes.

\section{Imaging of Oxygenation in the Tissue Compartment: ${ }^{19} \mathrm{~F}-\mathrm{MRI}$ and EPRI}

\section{$\left[{ }^{19} \mathrm{~F}\right]-\mathrm{MRI}$}

The relaxivity (R1) of contrast agents saturated with ${ }^{19}$ fluorine (such as perfluorocarbons or hexafluorobenzene administered either intravenously or directly in the brain tissue) is directly proportional to $\mathrm{p}_{\mathrm{t}} \mathrm{O}_{2}$. In a murine GBM model, Lemaire and colleagues (11) have shown the ability of $\left[{ }^{19} \mathrm{~F}\right]$-MRI to characterize the difference of tumor oxygenation between basal conditions $\left(\mathrm{p}_{\mathrm{t}} \mathrm{O}_{2} \approx 10 \mathrm{mmHg}\right.$ ) and during inhalation of $100 \%$ oxygen $\left(\mathrm{p}_{\mathrm{t}} \mathrm{O}_{2} \approx 170 \mathrm{mmHg}\right)$. Although $\left[{ }^{19} \mathrm{~F}\right]$-MRI is quantitative, this approach is limited by the potential toxicity of the tracer.

\section{Electron Paramagnetic Resonance Imaging}

Electron paramagnetic resonance (EPR) specifically responds only to atoms or molecules with unpaired electrons, including free radicals, free electrons, and some valence states of metal ions. The phenomenon that is observed with EPR is the transition (resonance absorption of energy) between the two energy states that can occur in an unpaired electron system placed within a magnetic field. This field separates the energy states associated with the two possible spin states of unpaired electrons. The presence of other unpaired electron species can affect the EPR spectrum. Molecular oxygen, with two unpaired electrons, can be detected either directly by EPR at ambient conditions due to fast relaxation of spins or detected indirectly from the oxygen-induced changes in the EPR spectrum of other paramagnetic probes in the system. From oxygen-induced EPR line bandwidth, one can quantify the oxygen concentration (12), in a preclinical study, have shown the ability and repeatability of electron paramagnetic resonance imaging (EPRI) to evaluate the different levels of oxygen in four brain tumor models. Furthermore, EPRI permits a spatial localization of $\mathrm{p}_{\mathrm{t}} \mathrm{O}_{2}$ (13). However, because the signal is weak in EPRI, the slice thickness is important and the spatial resolution relatively low.

\section{Assessment of Oxygenation at the Cellular Level: MOBILE and BLI}

\section{Mapping of Oxygen by Imaging Lipid relaxation Enhancement-MRI}

Because oxygen is 11 times more soluble in lipids than in water, it has been proposed to measure $\mathrm{T} 1$ relaxivity in lipids for the assessment of oxygen status (14). With GBM, this method holds promise given that the cerebral concentration of phospholipids is important in the brain. However, even if this method is sensitive to changes in $\mathrm{p}_{\mathrm{t}} \mathrm{O}_{2}$ during gas inhalation, for example, studies in brain tumors have yet to be performed.

\section{Bioluminescence Imaging}

Bioluminescence imaging (BLI) is based on the detection of light emitted by cells expressing a luciferase gene under the control of a hypoxia-sensitive promoter containing hypoxia response elements (HRE) sequences, has been advanced to measure brain hypoxia. An engineered human GBM cell line expressing luciferase under the control of HRE was implanted orthotopically and well correlated with other hypoxic reporters (15). Nonetheless, BLI has a low-spatial resolution and the tumoral heterogeneity will be difficult to assess and no translation to man is feasible.

\section{Assessment of Hypoxia with PET}

\section{${ }^{15}$ Oxygen}

The first PET radiotracer, used to assess oxygen levels in brain, was the positron emitter ${ }^{15}$ Oxygen which allowed several validated quantitative methods to map cerebral blood flow (CBF), $\mathrm{CBV}$, oxygen extraction fraction (OEF), and the cerebral metabolic rate of oxygen $\left(\mathrm{CMRO}_{2}\right)$ using ${ }^{15} \mathrm{O}$-labeled $\mathrm{H}_{2} \mathrm{O}, \mathrm{CO}$, and $\mathrm{O}_{2}(16)$. These methods are considered as the "gold standard" and are widely employed, among others, in the study of stroke.

However, these methods are not immediately translatable to oncology. Tumor metabolism is driven by the rate of glycolysis but without a corresponding increase in aerobic metabolism (the Warburg effect). In neoplasm, the inability of these techniques to reflect neither $\mathrm{p}_{\mathrm{t}} \mathrm{O}_{2}$ nor true $\mathrm{CMRO}_{2}$ has led to the development of various other PET tracers better adapted to this end. Two classes of radiotracers are employed: the $62 / 64 \mathrm{Cu}$ labeled-diacetyl-bis(N4-methylthiosemicarbazone) and ${ }^{18} \mathrm{~F}$-labeled nitroimidazoles analogs, discussed as follows.

\section{Cu-Diacetyl-bis(N4-Methylthiosemicarbazone) $\left({ }^{64} \mathrm{Cu}\right]$ or $\left.\left[{ }^{62} \mathrm{Cu}\right]-\mathrm{ATSM}\right)$}

$\left[{ }^{62} /{ }^{64} \mathrm{Cu}\right]$-ATSM has been promoted, not as an oxygen sensor, but as a hypoxia biomarker. $\mathrm{Cu}(\mathrm{II})$-ATSM is reduced to an unstable $\mathrm{Cu}(\mathrm{I})$-ATSM and then re-oxidized if oxygen is present but otherwise becomes trapped in hypoxic cells. This radiotracer has the capability to characterize moderate hypoxia with an enhanced uptake observed when $\mathrm{p}_{\mathrm{t}} \mathrm{O}_{2}$ is $<35 \mathrm{mmHg}$ (17). The long half-life of [ $\left.{ }^{64} \mathrm{CU}\right]-\operatorname{ATSM}(12.7 \mathrm{~h})$ is an advantage because production and transport would not only permit utilization in different clinical research centers but also a limitation in terms of radioprotection and the impossibility to repeat the measure more than once a week. With respect to neurooncology, Tateishi and colleagues (18) examined the interest of using $\left[{ }^{62} \mathrm{Cu}\right]$-ATSM for glioma grading and correlated $\left[{ }^{62} \mathrm{Cu}\right]$-ATSM uptake with HIF- $1 \alpha$ expression in glioma patients. However, several studies have suspected a nonspecificity of this radiotracer in hypoxia with an absence of correlation between the spatial distribution of $\left[{ }^{64} \mathrm{Cu}\right]$-ATSM uptake immunohistochemical characterization of hypoxia (19).

\section{Fluorinated Nitroimidazole Compounds}

Nitroimidazoles enter viable cells by passive diffusion where they undergo an active reduction. Under normoxic conditions, these molecules are re-oxidized and diffuse out of the cell. By contrast, in severe hypoxia, they eventually become irreversibly trapped 
in the cell at a threshold $\mathrm{p}_{\mathrm{t}} \mathrm{O}_{2}<10 \mathrm{mmHg}$. Several nitroimidazole radiotracers are at various stages of preclinical and clinical development.

\section{$\left[{ }^{18} \mathrm{~F}\right]$-Fluoromisonidazole ( $\left.{ }^{18} \mathrm{~F}\right]$-FMISO)}

Highly selective for hypoxia, $\left[{ }^{18} \mathrm{~F}\right]$-FMISO is the lead candidate to assess hypoxia with PET and is the most extensively studied radiotracer in clinical investigations. In high-grade glioma, where the $\mathrm{p}_{\mathrm{t}} \mathrm{O}_{2}$ in the tumor is remarkably low (around $7 \mathrm{mmHg}$ ), $\left[{ }^{18} \mathrm{~F}\right]-$ FMISO is increasingly used to estimate hypoxia (20). In our group, we have shown the ability of $\left[{ }^{18} \mathrm{~F}\right]$-FMISO to discriminate various states of hypoxia in different GBM models $(21,22)$. Others studies have shown that the uptake of $\left[{ }^{18} \mathrm{~F}\right]$-FMISO is inversely correlated to overall survival in GBM patients (23). The major limitation of this approach is the low sensitivity to moderate hypoxia (between 10 and $30 \mathrm{mmHg}$ ). The second limitation of this radiotracer is its relative long washout in non-hypoxic cells to obtain an optimal contrast (between 2 and $4 \mathrm{~h}$ after tracer injection).

\section{Other Hydrophilic Tracers \\ $\left[{ }^{18} \mathrm{~F}\right]-$ Fluoroazomycin-Arabinoside $\left(\left[{ }^{18} \mathrm{~F}\right]-\mathrm{FAZA}\right)$, \\ $\left[{ }^{18} \mathrm{~F}\right]-$ Flortanidazole $\left(\left[{ }^{18} \mathrm{~F}\right]-\mathrm{HX} 4\right)$ and \\ $\left[{ }^{18} \mathrm{~F}\right]$-Fluoroerythronitroimidazole $\left(\left[{ }^{18} \mathrm{~F}\right]-\mathrm{FETNIM}\right)$, 1-[2-[18 F] Fluoro-1-(Hydroxymethyl)- Ethoxy]Methyl-2-Nitroimidazole $\left(\left[{ }^{18} \mathrm{~F}\right]-\mathrm{RP}-170\right)$}

These tracers $\left(\left[{ }^{18} \mathrm{~F}\right]\right.$-Fluoroazomycin-arabinoside $\left(\left[{ }^{18} \mathrm{~F}\right]\right.$-FAZA), $\left[{ }^{18} \mathrm{~F}\right]$-Flortanidazole $\left(\left[{ }^{18} \mathrm{~F}\right]-\mathrm{HX} 4\right)$, and $\left[{ }^{18} \mathrm{~F}\right]$-fluoroerythronitro imidazole ([ $\left.{ }^{18} \mathrm{~F}\right]$-FETNIM), 1-[2-[ $\left[{ }^{18} \mathrm{~F}\right]$ Fluoro-1-(hydroxyme thyl)-ethoxy $]$ methyl-2-nitroimidazole ( $\left.\left[{ }^{18} \mathrm{~F}\right]-\mathrm{RP}-170\right)$ because of their hydrophilic character, have a more rapid plasma half-life and rapid clearance from tissues than $\left[{ }^{18} \mathrm{~F}\right]$-FMISO. $\left[{ }^{18} \mathrm{~F}\right]$-FAZA has been used to determine hypoxia in models of gliomas and discriminated clusters of hypoxia and necrosis $(24)$. $\left[{ }^{18} \mathrm{~F}\right]$-FAZA awaits clinical investigation for GBM patients. In glioma patients, $\left[{ }^{18} \mathrm{~F}\right]-\mathrm{RP}-170$ was compared to $\mathrm{p}_{\mathrm{t}} \mathrm{O}_{2}$ and HIF- $1 \alpha$ immunostaining and a selectivity of this tracer for hypoxia was observed (25). However, regarding their highly hydrophilic properties, these radiotracers are not recommended the study of brain tumors because their uptake will be largely influenced by BBB disruption (26).

\section{2-(2-Nitro-1H-imidazol-1-yl)-N-(2,2,3,3,3-penta- fluoropropyl)-acetamide ([18 F]-EF5)}

In contradistinction to the hydrophilic tracers, a lipophilic radiotracer, $\left[{ }^{18} \mathrm{~F}\right]$-EF5, has been studied to detect hypoxia in human GBM. Initially, it was used for immunohistochemistry, $\left[{ }^{18} \mathrm{~F}\right]-\mathrm{EF} 5$ possesses a sensitivity near to that of immunohistochemistry but the synthesis seems problematic (27).

\section{Interest of PET Tracers in the Management of GBM Patients}

The conventional treatment of GBM is surgical resection when possible, followed by radiotherapy along with concomitant chemotherapy. Despite these treatment protocols, the median survival fails to exceed 15 months. Imaging of hypoxia should ameliorate patient management in various ways (see Figure 1).

\section{Optimization of Conventional Treatments}

In the therapeutic management of glioma patients, it has been proposed to use imaging biomarkers of hypoxia to adapt the treatment according to hypoxic status (20). $\left[{ }^{18} \mathrm{~F}\right]$-FMISO seems particularly suited for the modulation of radiation dose in GBM because the range of $\mathrm{p}_{\mathrm{t}} \mathrm{O}_{2}$ identified by $\left[{ }^{18} \mathrm{~F}\right]$-FMISO (from 0 to $10 \mathrm{mmHg}$ ) corresponds to the scale used to define the radiation dose adapted for hypoxic, radioresistant tumors (28). Hence, authors have advanced the use of the spatial information derived from $\left[{ }^{18} \mathrm{~F}\right]$-FMISO to compute the prescription for the radiation dose (29). The aim of dose escalation is (i) to increase the efficacy of treatment in hypoxic area, (ii) to compensate for the spatial heterogeneity, and (iii) to reduce the toxicity to healthy tissue. While a boost of radiotherapy in the most hypoxic areas appears attractive, this concept still requires validation.

\section{Treatment Orientation}

Glioblastoma is densely vascularized tumors and, therefore, targeted anti-angiogenic therapies, such as bevacizumab, (a humanized monoclonal antibody raised against VEGF), has been suggested, although recent phase III trials demonstrated disappointing results. An explanation for the failure could be that no patient selection was performed prior to the initiation of the treatment. PET-based imaging of hypoxia could be performed before treatment to stratify eligible patients for the antiangiogenic strategy. After selection by markers of hypoxia, the use of radiosensitizers has also been proposed for head and neck cancers (EORCT trail 1219), an approach that could be applied to GBM patients. Our group has also demonstrated that hypoxiainducible genes, such as erythropoietin, are involved in GBM growth and resistance to treatment (5). Grounded on hypoxia imaging, such proteins would represent novel and original targets for therapy.

\section{Assessment of Treatment Effects}

The interest in anti-VEGF therapies has been rekindled since the emergence of the concept of "normalization." Anti-angiogenic treatments are now planned to transiently improve tumor vasculature, resulting in increased tumor perfusion and oxygenation. In a preclinical study in GBM, we have shown that sunitinib treatment decreases $\left[{ }^{18} \mathrm{~F}\right]$-FMISO uptake hypothetically due to vascular normalization (21). Similarly, Titz and colleagues (30) have proposed to program a model of responsivity to anti-angiogenic treatments from PET imaging of hypoxia in patients.

\section{Conclusion}

It is widely accepted that hypoxia is important not only in tumor growth but also in response to various therapeutic regimens. The characterization of oxygenation by non-invasive imaging remains a challenge for the management and adaptation of conventional treatments (radio- and chemotherapy) as well as to 
follow the efficacy of treatment. Several attempts have been made to develop methods to measure and image tumor oxygen tensions in vivo without consuming oxygen and thus without exacerbating the degree of hypoxia. Various approaches have been proposed to evaluate brain oxygenation at different scales from vascular to molecular levels. In this review, we argue that, despite development of several other methods (summarized Table 1), PET imaging (especially with fluorinated nitroimidazole compounds) seems to be, until now, the most relevant tool to characterize hypoxia in GBM.

\section{Author Contributions}

Manuscript drafting or manuscript revision for important intellectual content: all authors. Manuscript final version approval:

\section{References}

1. Beppu T, Kamada K, Yoshida Y, Arai H, Ogasawara K, Ogawa A. Change of oxygen pressure in glioblastoma tissue under various conditions. J Neurooncol (2002) 58:47-52. doi:10.1023/A:1015832726054

2. Inda M-D-M, Bonavia R, Seoane J. Glioblastoma multiforme: a look inside its heterogeneous nature. Cancers (Basel) (2014) 6:226-39. doi:10.3390/ cancers6010226

3. Vaupel P. Hypoxia and aggressive tumor phenotype: implications for therapy and prognosis. Oncologist (2008) 13(Suppl 3):21-6. doi:10.1634/theoncologist. 13-S3-21

4. Evans S, Jenkins K, Chen H. The relationship among hypoxia, proliferation, and outcome in patients with de novo glioblastoma: a pilot study. Transl Oncol (2010) 3:160-9. doi:10.1593/tlo.09265

5. Pérès EA, Gérault AN, Valable S, Roussel S. Silencing erythropoietin receptor on glioma cells reinforces efficacy of temozolomide and X-rays through senescence and mitotic catastrophe. Oncotarget (2015) 6:2101-19.

6. Tran L-B-A, Bol A, Labar D, Jordan B, Magat J, Mignion L, et al. Hypoxia imaging with the nitroimidazole 18F-FAZA PET tracer: a comparison with OxyLite, EPR oximetry and 19F-MRI relaxometry. Radiother Oncol (2012) 105:29-35. doi:10.1016/j.radonc.2012.04.011

7. Mehagnoul-Schipper DJ, van der Kallen BFW, Colier WNJM, van der Sluijs MC, van Erning LJTO, Thijssen HOM, et al. Simultaneous measurements of cerebral oxygenation changes during brain activation by near-infrared spectroscopy and functional magnetic resonance imaging in healthy young and elderly subjects. Hum Brain Mapp (2002) 16:14-23. doi:10.1002/hbm.10026

8. Christen T, Lemasson B, Pannetier N, Farion R, Segebarth C, Rémy C, et al. Evaluation of a quantitative blood oxygenation level-dependent (qBOLD) approach to map local blood oxygen saturation. NMR Biomed (2011) 24:393-403. doi:10.1002/nbm.1603

9. Lemasson B, Christen T, Serduc R, Maisin C, Bouchet A, Le Duc G, et al. Evaluation of the relationship between MR estimates of blood oxygen saturation and hypoxia: effect of an antiangiogenic treatment on a gliosarcoma model. Radiology (2012) 265:743-52. doi:10.1148/radiol.12112621

10. Baudelet C, Gallez B. Current issues in the utility of blood oxygen level dependent BOLD MRI for the assessmnent of modulation in tumor oxygenation. Curr. Med. Imaging Rev. (2005) 1:229-43. doi:10.2174/157340505774574754

11. Lemaire L, Bastiat G, Franconi F, Lautram N, Duong Thi Dan T, et al. (2013). Perfluorocarbon-loaded lipid nanocapsules as oxygen sensors for tumor tissue $\mathrm{pO}_{2}$ assessment. Eur J Pharm Biopharm 84:479-86. doi:10.1016/j.ejpb. 2013.01.003

12. Khan N, Mupparaju S, Hou H, Williams BB, Swartz H. Repeated assessment of orthotopic glioma $\mathrm{pO}(2)$ by multi-site EPR oximetry: a technique with the potential to guide therapeutic optimization by repeated measurements of oxygen. J Neurosci Methods (2012) 204:111-7. doi:10.1016/j.jneumeth.2011. 10.026

13. Matsumoto S, Saito K, Yasui H, Morris HD, Munasinghe JP, Lizak M, et al. EPR oxygen imaging and hyperpolarized 13C MRI of pyruvate metabolism as noninvasive biomarkers of tumor treatment response to a glycolysis inhibitor all authors. Literature research: AC-D, AC, SC, EM, OT, and SV. Manuscript editing: AC-D, EM, and SV. Figure preparation: AC-D, AC, EM, and SV.

\section{Acknowledgments}

This study was funded by the Institut National Contre le Cancer (INCa), the Centre National de la Recherche Scientifique (CNRS), the French Ministère de l'Enseignement Supérieur et de la Recherche (MESR), the University of Caen- Normandie (UNICAEN), the Conseil Régional de Basse-Normandie, the European Union-Fonds Européen de Développement Régional (FEDER) "L'Europe s'engage en Basse-Normandie," the French National Agency for Research called "Investissements d'Avenir" no. ANR11-LABEX-0018-01, ANR-11-BSV5-0004.

3-bromopyruvate. Magn Reson Med (2013) 69:1443-50. doi:10.1002/mrm. 24355

14. Jordan BF, Magat J, Colliez F, Ozel E, Fruytier AC, Marchand V, et al. Mapping of oxygen by imaging lipids relaxation enhancement: a potential sensitive endogenous MRI contrast to map variations in tissue oxygenation. Magn Reson Med (2013) 70:732-44. doi:10.1002/mrm.24511

15. Lo Dico A, Valtorta S, Martelli C, Belloli S, Gianelli U, Tosi D, et al. Validation of an engineered cell model for in vitro and in vivo HIF- $1 \alpha$ evaluation by different imaging modalities. Mol Imaging Biol (2014) 16:210-23. doi:10.1007/s11307013-0669-0

16. Moustafa RR, Baron J-C. Clinical review: imaging in ischaemic stroke - implications for acute management. Crit Care (2007) 11:227. doi:10.1186/cc5973

17. Toma-Dasu I, Dasu A, Brahme A. Quantifying tumour hypoxia by PET imaging: a theoretical analysis. Adv Exp Med Biol (2009) 645:267-72. doi:10.1007/9780-387-85998-9

18. Tateishi K, Tateishi U, Sato M, Yamanaka S, Kanno H, Murata H, et al Application of 62Cu-diacetyl-bis (N4-methylthiosemicarbazone) PET imaging to predict highly malignant tumor grades and hypoxia-inducible factor- $1 \alpha$ expression in patients with glioma. AJNR Am J Neuroradiol (2013) 34:92-9. doi:10.3174/ajnr.A3159

19. Carlin S, Zhang H, Reese M, Ramos NN, Chen Q, Ricketts S-A. A comparison of the imaging characteristics and microregional distribution of 4 hypoxia PET tracers. J Nucl Med (2014) 55:515-21. doi:10.2967/jnumed.113.126615

20. Cher LM, Murone C, Lawrentschuk N, Ramdave S, Papenfuss A, Hannah A, et al. Correlation of hypoxic cell fraction and angiogenesis with glucose metabolic rate in PET, and immunohistochemical studies. J Nucl Med (2006) 47:410-8.

21. Valable S, Petit E, Roussel S, Marteau L, Toutain J, Divoux D, et al. Complementary information from magnetic resonance imaging and (18)Ffluoromisonidazole positron emission tomography in the assessment of the response to an antiangiogenic treatment in a rat brain tumor model. $\mathrm{Nucl} \mathrm{Med}$ Biol (2011) 38:781-93. doi:10.1016/j.nucmedbio.2011.01.010

22. Corroyer-Dulmont A, Pérès EA, Petit E, Durand L, Marteau L, Toutain J, et al. Noninvasive assessment of hypoxia with 3-[18F]-fluoro-1-(2-nitro-1imidazolyl)-2-propanol ([18F]-FMISO): a PET study in two experimental models of human glioma. Biol Chem (2013) 394:529-39. doi:10.1515/hsz-2012-0318

23. Swanson KR, Chakraborty G, Wang CH, Rockne R, Harpold HLP, Muzi M, et al. Complementary but distinct roles for MRI and 18F-fluoromisonidazole PET in the assessment of human glioblastomas. J Nucl Med (2009) 50:36-44 doi:10.2967/jnumed.108.055467

24. Belloli S, Brioschi A, Politi LS, Ronchetti F, Calderoni S, Raccagni I, et al. Characterization of biological features of a rat F98 GBM model: a PET-MRI study with [18F]FAZA and [18F]FDG. Nucl Med Biol (2013) 40:831-40. doi:10. 1016/j.nucmedbio.2013.05.004

25. Beppu T, Terasaki K, Sasaki T, Fujiwara S, Matsuura H, Ogasawara K, et al. Standardized uptake value in high uptake area on positron emission tomography with 18F-FRP170 as a hypoxic cell tracer correlates with intratumoral oxygen pressure in glioblastoma. Mol Imaging Biol (2014) 16:127-35. doi:10. 1007/s11307-013-0670-7 
26. Fleming IN, Manavaki R, Blower PJ, West C, Williams KJ, Harris AL, et al. Imaging tumour hypoxia with positron emission tomography. $\mathrm{Br} \mathrm{J}$ Cancer (2015) 112:238-50. doi:10.1038/bjc.2014.610

27. Koch CJ, Scheuermann JS, Divgi C, Judy KD, Kachur AV, Freifelder R, et al. Biodistribution and dosimetry of 18F-EF5 in cancer patients with preliminary comparison of 18F-EF5 uptake versus EF5 binding in human glioblastoma. Eur J Nucl Med Mol Imaging (2010) 37:2048-59. doi:10.1007/s00259-010-1517-y

28. Spence AM, Muzi M, Swanson KR, O’Sullivan F, Rockhill JK, Rajendran JG, et al. Regional hypoxia in glioblastoma multiforme quantified with $[18 \mathrm{~F}]$ fluoromisonidazole positron emission tomography before radiotherapy: correlation with time to progression and survival. Clin Cancer Res (2008) 14:2623-30. doi:10.1158/1078-0432.CCR-07-4995

29. Toma-Dasu I, Uhrdin J, Antonovic L, Dasu A, Nuyts S, Dirix P, et al. Dose prescription and treatment planning based on FMISO-PET hypoxia. Acta Oncol (2012) 51:222-30. doi:10.3109/0284186X.2011.599815
30. Titz B, Kozak KR, Jeraj R. Computational modelling of anti-angiogenic therapies based on multiparametric molecular imaging data. Phys Med Biol (2012) 57:6079-101. doi:10.1088/0031-9155/57/19/6079

Conflict of Interest Statement: The authors declare that the research was conducted in the absence of any commercial or financial relationships that could be construed as a potential conflict of interest.

Copyright (c) 2015 Corroyer-Dulmont, Chakhoyan, Collet, Durand, MacKenzie, Petit, Bernaudin, Touzani and Valable. This is an open-access article distributed under the terms of the Creative Commons Attribution License (CC BY). The use, distribution or reproduction in other forums is permitted, provided the original author(s) or licensor are credited and that the original publication in this journal is cited, in accordance with accepted academic practice. No use, distribution or reproduction is permitted which does not comply with these terms. 